\title{
Unfolding the simple heuristics of smart solution development
}

\author{
Tuomas Huikkola
}

School of Management, University of Vaasa, Vaasa, Finland

Marko Kohtamäki

School of Management, University of Vaasa, Vaasa, Finland; Entrepreneurship and Innovation, Lulea University of Technology, Luleà, Sweden and

USN Business School, University of South-Eastern Norway, Kongsberg, Norway

Rodrigo Rabetino

Department of Management, University of Vaasa, Vaasa, Finland

Hannu Makkonen

School of Marketing and Communications, University of Vaasa, Vaasa, Finland, and

Philipp Holtkamp

Innovation Office, University of Vaasa, Vaasa, Finland

\begin{abstract}
Purpose - The present study intends to foster understanding of how a traditional manufacturer can utilize the "simple rules" approach of managerial heuristics to facilitate its smart solution development (SSD) process. Design/methodology/approach - The study uses an in-depth single case research strategy and 25 senior manager interviews to understand the application of simple rules in smart solution development.

Findings - The findings reveal process, boundary, preference, schedule, and stop rules as the dominant managerial heuristics in the case and identify how the manufacturer applies these rules during the innovation process phases of ideation, incubation, transformation, and industrialization for attaining project outcomes.

Research limitations/implications - The study contributes to the new service development (NSD) literature by shedding light on simple rules and how managers may apply them to facilitate SSD. The main limitations stem from applying the qualitative case study approach and the interpretative nature of the study, which produces novel insights but prevents direct generalization to other empirical cases.

Practical implications - The resulting framework provides guidelines for managers on how to establish formal and clear simple rules that enable industrial solution providers to approach decision-making in smart solution development in a more agile manner.

Originality/value - The study comprises one of the first attempts to investigate managerial heuristics in the context of SSD and puts forward a plea for further NSD research applying psychological conceptualizations to enrich the simple rules perspective.
\end{abstract}

Keywords Heuristics and simple rules, Innovation management and innovation process, New service development, Smart solution development and strategic agility, Digital servitization and product-service systems (PSS)

Paper type Research paper

(C) Tuomas Huikkola, Marko Kohtamäki, Rodrigo Rabetino, Hannu Makkonen and Philipp Holtkamp. Published by Emerald Publishing Limited. This article is published under the Creative Commons Attribution (CCBY 4.0) licence. Anyone may reproduce, distribute, translate and create derivative works of this article (for both commercial and non-commercial purposes), subject to full attribution to the original publication and authors. The full terms of this licence may be seen at http://creativecommons. org/licences/by/4.0/legalcode.

This paper forms part of a special section "The Future of Servitization in a Digital Era (Part 2)", guest edited by Christian Kowalkowski, Tim Baines and Ali Ziaee Bigdeli.
Received 26 November 2020

Revised 6 May 2021 28 August 2021 26 October 2021 Accepted 27 October 2021 
JOSM

33,1

122

\section{Introduction}

In search of higher economic returns and competitive advantage, equipment manufacturers have engaged in delivering a variety of smart solutions to extend their core offerings; a strategic transition acknowledged as digital servitization (Sklyar et al., 2019; Paschou et al., 2020; Tronvoll et al., 2020). Manufacturers develop smart solutions, defined as bundles of products, services, and software systems, to cocreate higher customer value to enable industrial clients to gain productivity leaps in their business fields (Korkeamäki et al., 2021). To achieve the benefits of smart solutions despite increasing competition, manufacturers have to improve managerial decision-making processes and routines of smart solution development (SSD) (Porter and Heppelmann, 2014; Kohtamäki et al., 2020). Studies on managerial heuristics suggest using simple rules for complex and dynamic operational environments (Sull and Eisenhardt, 2015). However, the role of heuristics in smart solution development is unexplored.

The existing literature on new service/solution development (NSD) has studied the evolution of processes (Panesar and Markeset, 2008), capabilities (Kindström et al., 2013), routines (Solem et al., 2021), innovation modes (Gremyr et al., 2014), and customer knowledge development (Johansson et al., 2019) among manufacturers engaged in servitization. Although there are studies investigating decision making in servitization (Cui et al., 2019; Dahmani et al., 2020) and NSD (see Kindström and Kowalkowski, 2009), little is yet known about managerial heuristics and, in particular, "simple rules" that guide how yes/no decisions are made in practice (Huikkola and Kohtamäki, 2021). Some previous studies have focused on a rational and slow decision-making approach among manufacturers engaged in servitization, but agile decision-making routines have not been given a particular emphasis (Kristensson and Magnusson, 2019). This deficiency of evidence of managerial decision making restricts our understanding of how manufacturers manage their new smart solution innovation processes in situations where there are always more opportunities to pursue than resources to do so and when digitalization makes the business environment more complex, turbulent, and foggy. Indeed, Paschou et al. (2020, p. 278) call for research on decision making when managing innovation development: "This picture calls for future research endeavors to extend the scope of investigation into digital servitization (regarding the technologies covered and their combinatory effect, the potential benefits, and the application domains) and to develop models and frameworks to support decision-making by practitioners."

Drawing on these observations, the present study addresses the following research question: How can a manufacturer utilize simple heuristics in smart solution development? We conduct an in-depth single case study of a leading smart solution provider to observe the simple heuristics that a manufacturer deliberately applies to manage new smart solution development processes in a fast and frugal manner. The study contributes to the NSD literature by identifying how simple rules, namely, process, boundary, preference, schedule, and stop heuristics, help manufacturers develop new smart solutions. For managers, the study provides "simple rules" as guidelines for managing smart solution development in practice.

This paper has five main sections. First, the introduction section motivates the study, shows the research gap, and positions the paper. Section 2 discusses the theoretical premises of the paper regarding digital servitization, SSD, and managerial heuristics. Next, the third section opens the methodological choices of our in-depth single case study to address the research question. The fourth section illustrates the key findings of simple heuristics applied to manage SSD. Finally, the last section discusses the theoretical and managerial contributions of the paper as well as its fundamental limitations and guidelines for future research. 


\section{Theoretical background}

\subsection{Digital servitization and smart solution development in manufacturing companies}

The servitization literature interprets digital servitization as a substream of servitization research, emphasizing digital tools (Kohtamäki et al., 2019; Raddats et al., 2019; Rabetino et al., 2021a). Typically, defined as "the utilization of digital tools for "the transformational processes whereby a company shifts from a product-centric to a service-centric business model and logic" (Kowalkowski et al., 2017, p. 8; Sklyar et al., 2019, p. 450), digital servitization refers to a manufacturer's transition from selling products to selling advanced product-service-software systems (Hsuan et al., 2021). This strategic evolution is profound and contains a leap from efficiency-driven product logic toward customer-driven service logic (Kowalkowski and Ulaga, 2017; Töytäri et al., 2018) that requires the development of new solutions through digital technologies such as the internet of Things (IoT) and artificial intelligence (AI) (Sklyar et al., 2019; Paiola and Gebauer, 2020; Paschou et al., 2020). Extant studies on digital servitization have found that manufacturers need to reposition in the ecosystem (Kohtamäki et al., 2019), alter their capabilities (Coreynen et al., 2020), change their intra- and interfirm processes (Markovic et al., 2020; Sklyar et al., 2019), and collaborate with knowledge-intensive business service firms (Bustinza et al., 2020b) to enable the transition and achieve both economic and strategic benefits (Vendrell-Herrero et al., 2017). Moreover, studies have suggested managerial sayings (Korkeamäki et al., 2021) and doings as practices (Kohtamäki et al., 2018, 2021; Palo et al., 2019) to manage this strategic transition. For instance, executives' speeches and public statements steer manufacturers' actual doings, such as investment decisions, acquisitions, or resourcing, regarding new solution development (Huikkola et al., 2020; Kohtamäki et al., 2021).

Complex structural contexts, such as smart solution development, might benefit from sophisticated management systems (Rabetino et al., 2017), mainly managerial heuristics that guide managers when making difficult decisions in rapidly changing situations (Bingham et al., 2019). Manufacturers typically develop new smart solutions to pursue digital servitization strategies (Allmendinger and Lombreglia, 2005; Sjödin et al., 2020a, b). The term "smart" refers to intelligent elements inside the solution that connect solutions to the client's other systems through ports, protocols, and internet-enabled technologies such as the IoT (Porter and Heppelmann, 2015) that enable data collection and sharing within the ecosystem (Jovanovic et al., 2019; Tian et al., 2021). "Solution" refers to a bundle of products, services, and software that create more value for the client when they are integrated, compared to an alternative where they are sold separately (Nordin and Kowalkowski, 2010). In particular, the incorporation of the software element calls for a change in the manufacturer's internal processes and decision-making routines, as the development cycles are much faster than in traditional new product and service innovations (Immelt, 2017). Managers should develop decision-making processes (Ott and Eisenhardt, 2020) and heuristics to manage the development of smart solutions more effectively as development cycles become shorter than before and the complexity of both offerings and the environment increases.

\subsection{Managerial decision-making within the strategic transition of the firm}

Managerial decision-making has recently gained interest among servitization scholars (Cui et al., 2019; Dahmani et al., 2020). When firms undergo strategic transitions such as (digital) servitization, managers need to pay special attention to making decisions in risky and complex settings. Traditionally, servitization studies have emphasized rational and slow thinking to manage this transition effectively (Cui et al., 2019; Kristensson and Magnusson, 2019). However, in practice, managers tend to make decisions on autopilot, relying on a fast, frugal, and even intuitive decision-making approach based on heuristics (Huikkola and Kohtamäki, 2021). According to Tversky and Kahneman (1974), heuristics function as mental 
JOSM

33,1

124

shortcuts providing fast and frugal managerial decision-making approach (Gigerenzer, 2008) that works best in turbulent environments such as in high-velocity markets (Sull and Eisenhardt, 2012). Thus, managerial heuristics are management practices employed to resolve issues that logic and probability theory cannot handle (Artinger et al., 2015). They can be beneficial when there is too little or too much information available to make decisions (Maitland and Sammartino, 2015) or when organizations lack the time or resources to properly analyze a subject (Bingham and Eisenhardt, 2014). Managerial heuristics are particularly useful when studying strategic processes (Bingham and Eisenhardt, 2014), such as new solution development, in which a systematic analysis of all the possibilities is likely to be out of a firm's scope (Sull and Eisenhardt, 2015).

However, use of heuristics when making (strategic) decisions can lead to adverse (Kahneman, 2011), better (Bingham and Eisenhardt, 2014), or mixed results (Wübben and Wangenheim, 2008). Adverse results typically arise from managers' universal framing and anchoring errors, cognitive biases, and the dominance of System 1 thinking (fast and intuitive thinking; see Kahneman, 2011). In contrast, better results emerge from the process of learning through repetition and experience (trial-and-error) (Antretter et al., 2020; Bingham and Eisenhardt, 2011). Because heuristics are the opposite of rational decision making (System 2/slow and rational thinking), some scholars (e.g. Kahneman, 2011) have provided data that show them leading to worse results. However, other scholars (e.g. Artinger et al., 2015) have found that heuristics can lead to ecological and economic benefits when a company is operating with unclear goals or incomplete information (Gigerenzer and Gaissmaier, 2011). Bingham and Eisenhardt (2014) argue that the use of heuristics in decisionmaking can even lead to better results.

According to Kahneman and Klein (2009), heuristics-based decision making probably works better under predictable conditions where the decision maker has already learned the patterns of the business context. Rarely, if ever, firms operate in environments where information would be complete, where all relevant alternatives could be recognized, after which a rational decision maker would make a strategic decision (Gigerenzer and Gaissmaier, 2011). Vuori and Vuori (2014) note that the use of heuristics in the context of strategizing works differently than in the laboratory contexts employed by Kahneman and Gigerenzer because real-life strategizing involves less redundancy and stability, the timeframe for decision making is longer, and the key users of heuristics are teams instead of individuals. Bingham and Eisenhardt (2014) note that simple heuristics work best when managing strategic processes such as new service/solution development or internationalization because these processes are easily understood and adopted by personnel. Among practitioners, heuristics typically take the form of simple rules (Eisenhardt and Sull, 2001) that can be categorized based on their inherent nature. These simple rules reflect what actual content managers and firms have learned along the way (Bingham and Eisenhardt, 2011). Simple rules are thus rooted in accumulated process experience and reflect their know-how regarding process management (Bingham and Eisenhardt, 2011). As the establishment of simple rules requires time and process experience (Ott and Eisenhardt, 2020), they are viewed similar to "expert heuristics" in our study (Bingham and Eisenhardt, 2011), indicating that they are opposite to an ad hoc type of thinking and that their formation reflects seniority and experience of learning.

\section{3 "Simple rules" in the new smart solution development}

Eisenhardt and Sull (2001) present five types of simple rules that can be implemented when deciding how to manage different aspects of dedicated strategic processes: how-to, boundary, priority, timing, and exit rules. How-to rules present key features of how a specific strategic process is executed in practice (Eisenhardt and Sull, 2001). How-to rules are beneficial in the 
context of high pressure and severe time constraints by providing organization members with the flexibility to execute specific processes and opportunities (Bingham and Eisenhardt, 2011). Boundary rules help managers sort and pursue many opportunities quickly and economically. Boundary rules guide yes-or-no decisions, narrowing down the available alternatives without requiring a significant amount of time, analysis, or information to make a proper judgment of a subject. Thus, boundary rules address the basics of what to do or not to do (Eisenhardt and Sull, 2001). Priority rules, however, address the challenge of ranking opportunities. They can be used in corporations to rank products and services (e.g. assigning engineers to NSD projects) (Sull and Eisenhardt, 2015). Timing rules focus on the pace at which opportunities are executed (Bingham and Eisenhardt, 2011) and address, for instance, the maximum amount of time that the development of a new solution may take (Eisenhardt and Sull, 2001). Exit rules concern decisions to reject opportunities or withdraw from prior opportunities.

Building on Eisenhardt and Sull's (2001) categorization, we propose five types of simple heuristics for the different phases of new solution development (ideation, incubation, transformation, and industrialization; see Huikkola and Kohtamäki, 2020): process heuristics (how-to rules), boundary heuristics (boundary rules), preference heuristics (priority rules), schedule heuristics (timing rules), and stop heuristics (exit rules). Figure 1 outlines the overall framework of the study, namely, different types of simple rules to manage both product and smart solution development initiatives. The left side refers to rules regarding the new product development (NPD) logic associated with a highly analytical and rational decision-making

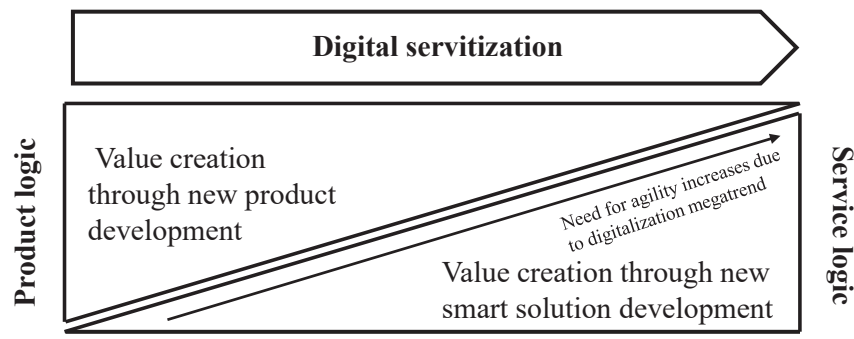

\begin{tabular}{|ccc|}
\hline $\begin{array}{c}\text { Analytical, complex, } \\
\text { and time-consuming }\end{array}$ & $\begin{array}{c}\text { Key approach to } \\
\text { decision-making }\end{array}$ & $\begin{array}{c}\text { Fast, simple, } \\
\text { and frugal }\end{array}$ \\
\hline
\end{tabular}

Types of simple heuristics

\begin{tabular}{|ccc|}
\hline $\begin{array}{c}\text { How to develop } \\
\text { new products }\end{array}$ & Process heuristics & $\begin{array}{c}\text { How to develop } \\
\text { new smart solutions (SS) }\end{array}$ \\
\hline
\end{tabular}

\begin{tabular}{|ccc|}
\hline $\begin{array}{l}\text { How to guide to make yes/no } \\
\text { decision regarding products }\end{array}$ & Boundary heuristics & $\begin{array}{l}\text { How to guide to make } \\
\text { yes/no decision regarding SS }\end{array}$ \\
\hline $\begin{array}{c}\text { How to rank } \\
\text { new product opportunities }\end{array}$ & Preference heuristics & $\begin{array}{l}\text { How to rank new } \\
\text { SS opportunities }\end{array}$ \\
\hline
\end{tabular}

\begin{tabular}{|llc|}
\hline \multicolumn{1}{|c}{$\begin{array}{c}\text { How to time new } \\
\text { product opportunities }\end{array}$} & Schedule heuristics & $\begin{array}{c}\text { How to time } \\
\text { SS opportunities }\end{array}$ \\
\hline $\begin{array}{l}\text { How to exit or withdraw from } \\
\text { opportunities regarding } \\
\text { poroducts }\end{array}$ & Stop heuristics & $\begin{array}{l}\text { How to exit or withdraw from } \\
\text { opportunities regarding SS }\end{array}$ \\
\hline
\end{tabular}

Figure 1. Research framework 
JOSM 33,1 approach (slow thinking). Instead, the right side of the figure accords with rules related to smart solution development logic that can be described following the heuristics approach to decision making. Naturally, these dichotomies are simplified, as NPD may follow fast and frugal managerial heuristics, and SSD may follow a traditional, more analytical approach to decision making. However, generally, as the business environment becomes more turbulent because of the megatrend of digitalization, traditional industrial manufacturers need to rely on heuristics to cope with increased speed and complexity, as examples from high-velocity industries indicate (Bingham et al., 2019; Ott and Eisenhardt, 2020).

\section{Methodology}

\subsection{Research design and case selection}

We utilized an in-depth single case study method to understand solution providers' managerial heuristics in the context of new smart solution development. The method is appropriate when the studied phenomenon is complex and novel (Piekkari et al., 2010), as with new smart solution development. We selected the solution innovation process of one global solution provider to be studied because (1) it is one of the leading firms in its industry, it sells and delivers a wide range of (smart) solutions to its industrial customers ranging from engine-as-a-service to complex operations and maintenance solutions, (2) the company servitized its business many years ago and renewed its innovation model a few years ago to increase its strategic agility and clock speed, namely, to decrease a new solution's time-tomarket and improve the hit rate of its solutions, and (3) we have continuous research collaboration with this firm that grants wide access to research data and provides us with a contextual understanding of the case. The studied case company has defined itself as a global leader in smart technologies and lifecycle solutions for the marine and energy sectors. Thus, the purposefully selected case company provides an interesting and powerful case to study simple heuristics in the context of new solution development (Siggelkow, 2007) and gain interesting insights to aid managers responsible for new solution development (Patton, 2002). The researchers have collaborated with this firm for a relatively long time (some research members have $>15$ years of collaboration experience, and one author has been responsible for innovation process development within the firm).

\subsection{Data collection}

As a first initiative, we examined extensive archival data on the firm to recap the evolution of the service business over the years. These data summarized the firm's strategic initiatives in the markets, how it has attempted to differentiate itself in the markets, and how it has endeavored to address the changes in its sectors.

The data were collected in two interview rounds. In the first interview round between 2016 and 2018, we interviewed 12 senior managers from different business disciplines to understand the firm's business strategy, landscape, and sources of competitive advantage in the markets and key rigidities, strengths, challenges, and market opportunities. In the second interview round between 2019 and 2020, we conducted 13 manager interviews to understand how the corporation's new innovation model launched in 2017 had been adopted among the organization's members, what have been the reasons for its establishment, and interpretations of the early effects of the model. These managers were chosen because they were responsible for developing and executing innovations. These interviews lasted from 35 to $90 \mathrm{~min}$, with an average research interview taking approximately $64 \mathrm{~min}$. Altogether, we conducted 25 interviews with managers to understand why the new model was established, how new solution innovations are managed, and how simple rules are utilized to guide their development. All of the interviews were audiotaped and transcribed verbatim, resulting in almost 380 pages of transcripts. Table 1 below briefly describes the primary interview data collected. 
First interview round 2016-2018

Relevant

industry

Job title

experience

Business Development Director

N/A

Sales and Business Development Director

N/A

Director 1, Solutions

Director 2, Solutions

31

O\&M Director

General Manager (GM), Sales Operations

Development Manager

19

20

19

Strategic Alliances Manager

Digitization Director 14

Service Unit Director 23

Marketing Director 38

Maintenance Director 20

$\begin{array}{ll}\text { Average } & 21.36 \text { years }\end{array}$

$\begin{array}{ll}\text { Median } & 20 \text { years }\end{array}$

Second interview round 2019-2020

Senior Project Manager*4 20

GM, Innovation*2 12

GM, Open Innovation $\quad 28$

Program Director 26

General Manager, Innovation Process 24

Director, Delivery Centre 18

GM, Ecosystem Innovation $\quad 17$

Service Designer

Innovation Manager 14

Average

14.89 years

$\begin{array}{ll}\text { Median } & 18 \text { years }\end{array}$

Table 1.

Primary data description

After familiarizing ourselves with the literature on new solution development and servitization, we deployed our first semistructured questionnaire (see Appendix 1). This questionnaire focused on servitization in general and new service development. Shortly after this, we obtained the case company's new innovation model that helped us craft a new template for new smart solution development (see Appendix 2). This step enabled us to obtain an in-depth understanding of general processes, routines, and practices during each development mode (ideation, incubation, transformation, and industrialization). Furthermore, we focused on understanding the managerial heuristics employed during each development phase. Table 2 describes how we have addressed this interpretative study's trustworthiness. Criteria have been drawn based on work by Eriksson and Kovalainen (2008), Lincoln and Guba (1985), and Strauss and Corbin (1998), and recent qualitative servitization studies (Storbacka, 2011; Raja et al., 2020).

\subsection{Analysis of the data}

The qualitative content analysis method was utilized to analyze the data concerning managerial heuristics theory in a new solution development context. The respondents' answers were coded into first-order concepts representing the respondents' original language to describe the examined phenomenon (Corley and Gioia, 2004). During the next phase, following Corley and Gioia's (2004) approach of analyzing data, we conducted a second-order theme analysis that emerged from the first-order items' analysis. These second-order themes 
JOSM 33,1

128

Criteria
Preunderstanding of the subject
(familiarity of the researchers with the
studied phenomenon)

Credibility (how well the results appear to represent the data)

Transferability (how well the results can be applied)

Dependability (how consistent the explanations are)

Objectivity (how the results from the respondents were interpreted and how researchers' biases were avoided)

Integrity (how the respondents may give misinformation regarding the phenomenon)

Understanding (how the results represent real-world circumstances)

Table 2.

Study's trustworthiness
The method used to address the criteria References

The authors have $10+$ years of servitization research experience The authors have collaborated with the firm for over ten years and are involved in different business-related research projects

The authors have conducted multiple executive and manager interviews within this company

The authors have one published article on the subject

The authors have $>1$ year of continuous interaction with the firm's representatives involving member checks

The case firm provided the framework used for research purposes

The case firm provided access to senior manager interviews

The case firm provided additional documents (e.g. the innovation playbook) for research purposes The first round of interviews was conducted between 2016 and 2018 The second round of interviews was conducted in 2019-2020

The Gioia method was used to represent the data structure

Use of purposeful sampling (results can be potentially applied to similar contexts)

Twenty-five managers were interviewed altogether The interviews were audiotaped and transcribed verbatim afterward The interpretations were confirmed with the case firm's representatives Multiple researchers were involved in reducing researcher bias

The interviews were professional, friendly, and anonymous

Several managers from the company were interviewed to avoid singlerespondent bias (enabled data triangulation)

Each manager was interviewed separately (no group interviews) to avoid potential problems caused by the group interviews

The preliminary findings were presented to the managers The preliminary findings were Huberman and Miles (1994), Lincoln and Guba (1985)

Storbacka (2011)

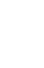


were related to needs for the new model establishment, different types of simple heuristics such as process, boundary, preference, schedule, stop rules, and positive effects of the new model. As a final step, the aggregate (third-order) dimension represents the most abstract dimension. These aggregate dimensions are triggers for the new solution development model, simple heuristics under different phases of innovation, namely, ideation, incubation, transformation, and industrialization, and experiences of the new model's early effects. Figure 2 represents the study's overall data structure.

\section{Simple heuristics of SSD}

\subsection{Case description}

Our study's unit of analysis is a case firm's new (solution) innovation process. The studied company is an international integrated solution provider that has been recognized as one of the leading technology developers in its sectors (see Salonen and Jaakkola, 2015), services accounting for $50 \%$ of its revenues in 2018. Recently, the firm has begun to pursue its vision of becoming a smart integrated solution provider, indicating that its new digital technologies will be key facilitators of more sustainable and networked ecosystems. To achieve this vision, the firm has paid particular attention to developing smart solutions. This activity has resulted in an increased number of software-based acquisitions, collaborations with start-ups and universities, and the development of new smart, connected offerings (e.g. a solution that enables the operation of a harbor tug in a smarter, safer, and more efficient way). As the studied company is a publicly listed company, a large amount of secondary data from this organization is available for research purposes (e.g. press releases, annual reports, histories, strategy documents, and public presentations). Furthermore, through research collaborations in different university-firm collaborations and research projects related to digital servitization, researchers have obtained strategy documents over the years that help researchers evaluate the company's transition to smart solutions over a longer period.

\section{Findings}

This study starts with explicating new solution development process model triggers and interprets how managerial heuristics enable each solution development phase. In the form of "simple rules", these heuristics guide people in the examined firm to manage its solution innovation process flexibly and agilely, providing clear and straightforward rules that determine when to continue or stop new solution development. Early experiences and effects of the employment of the new model are briefly described at the end of this section.

\subsection{Triggers for a new solution development process model}

The case firm wanted to break free from its established product- and technology-based development models that were considered relatively rigid in today's business environment. As one innovation manager responded: "Our [development] models have been developed to serve our R\&D and technology development level issues ... They have been quite rigid. They're quite heavy. However, they are giving us the foundations that we need. Maybe that's the only way forward to achieve agility or something". The key managers considered that resources were not adequately allocated between previous development projects, as the following quote from the GM (open innovation) represents: "It has been an unacceptable waste of resources because there have been too many things going on simultaneously and they have not been prioritized properly". Furthermore, top management was considered a driving force to push novel ideas and new solutions quicker to the markets, as an interviewed innovation manager noted: "Our priority is now to generate something new".

Overall, established models were product- and technology-oriented, and they were not considered optimal to create new solutions fast enough to bring to market. These new 
JOSM

33,1

130

Figure 2.

The data structure of the study

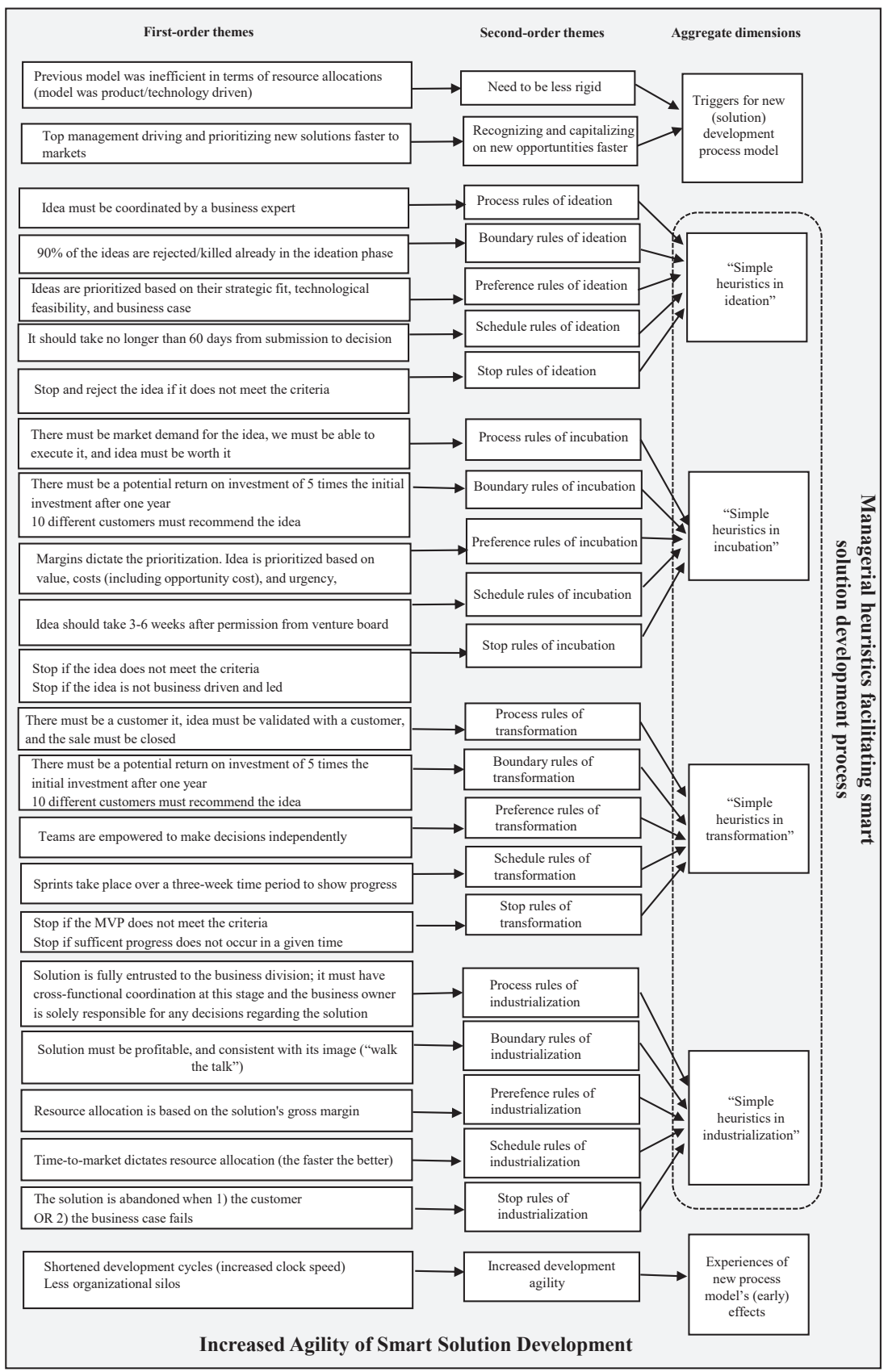


solutions require cooperation between different units and fast validation. To develop solutions faster for market introduction, the case company and a large international consulting company established a new innovation model consisting of ideation, incubation, transformation, and industrialization phases. These phases embedded heuristics that were developed based on accumulated experiences.

\subsection{Simple heuristics in ideation}

The ideation phase concerns both new ideas and opportunity exploration within markets (Teece, 2007). The process of taking advantage of an existing business in a market is referred to as exploitative behavior (Sirén et al., 2012), whereas seeking opportunities outside a firm's current scope is referred to as explorative behavior (Bustinza et al., 2020a). Firms that can engage in these behaviors simultaneously are called "ambidextrous organizations" (Birkinshaw and Gibson, 2004). There are typically many ideas within a firm to choose from, and firms have limited resources to proceed with most of them. Hence, firms need to craft specific rules to identify which ideas to pursue and which to reject. At the studied case firm, managers noticed that ideas tended to come from the same personnel group. To increase the number of ideas produced, managers established new social media-based tools to facilitate ideation among the organization's members. The managers reported that 1,500 ideas per year were placed into the ideation system. At this point, the firm needed to address the following question: "Is this idea's value potential worth pursuing further?" This step was necessary because the amount of resources and attention needed during future stages increases remarkably, as one senior project manager noted: "The ideation phase is timeconsuming rather than cash-consuming”.

Drawing on accumulated experience, the firm's managers created a process rule stating that "ideas must be coordinated by a business expert". This rule ensured that a business viewpoint was always present when proceeding with ideas or deciding if an idea should be rejected. To manage expectations both internally and externally, an indirect boundary rule was crafted: "90\% of the ideas are rejected" to govern the ideation phase. This experience resembles Osterwalder et al. (2020) findings from other companies' innovation initiatives. The long history of the case firm as an engineering company still casually reflects a production rather than market orientation, and the managers explained that their engineers typically developed ideas that did not always have obvious commercial applications. The firm's innovation managers wanted to tackle this challenge by formulating a preference rule, namely, that ideas "are evaluated based on their (1) strategic fit, (2) technological feasibility, and (3) business case". As a schedule rule, the firm's managers stated that "ideas should take a maximum of 60 days from submission to a decision". This rule enabled the firm to accelerate its ideation initiative, increasing organization members' motivation to contribute to ideation. If an idea did not meet the criteria above, the stop rule would be applied, and the idea would be rejected. Thus, the firm proceeded with only the ideas that met the criteria, as these ideas were valuable and worth pursuing further.

\subsection{Simple heuristics in incubation}

Incubation is an optional phase that is meant to address the following question: "Has this idea been validated with customers and the business division to build a minimum viable product (MVP)?" This phase must show that ideas (1) make sense for customers and (2) are economically feasible for the company. As a process rule for the incubation phase, employees must answer the three following questions affirmatively: (1) Is there market demand for the concept? (2) Can we do it? (3) Is it worth it? To address these questions, personnel need to conduct customer interviews, evaluate the business potential of a concept, and evaluate a 
JOSM 33,1

firm's capabilities to execute the concept. To create a concept and build a business case, the firm's general manager (innovation) described the following boundary rule: "There must be a potential return on investment of five times the initial investment after one year". To illustrate this better, a $200,000 €$ investment should generate at least 1 million $€$ for the company after one year. Furthermore, managers responsible for the firm's innovation process management crafted another boundary rule stating that "at least ten customer interviewees from different customer segments and locations should recommend the idea/concept". To prioritize the different concepts, a preference rule was stipulated stating that concepts are prioritized based on (1) value (margins), (2) costs (including opportunity costs), and (3) urgency. The schedule rule indicates that "concept validation should take 3-6 weeks after the decision is made by the permission board". As a stop rule, if a concept is not business-driven or does not meet the criteria mentioned above, it should be abandoned.

\subsection{Simple heuristics in transformation}

The transformation phase determines an MVP's value and urgency and dictates whether the concept should be resourced to continue larger-scale development. During this phase, a firm must address the following question: "Have customers and the business division validated this MVP's complexity and urgency to justify its launch and continue largerscale development?" Two key process rules dictate the success of this phase: (1) there must be a customer for the concept (customers must be interested in the concept), and (2) there must be a way to sell it (customers need to use their own money to buy it). An algorithm can be used to validate these rules. The transformation phase follows the same boundary rules as the incubation phase (the value potential should be five times the required investment +10 customer recommendations). No dedicated preference rules govern the transformation phase; instead, innovation managers reported that teams prioritize projects independently. Thus, teams are empowered to select projects to pursue, reminiscent of Netflix's well-known "no rules rules" model (Hastings and Meyer, 2020). The schedule rule states that "sprints must be done in three weeks to show progress". This task can take 18 months (or more), but development occurs in three-week sprint cycles. If the firm's managers do not see sufficient progress, the stop rules will be applied, and the MVP will be abandoned.

\subsection{Simple heuristics in industrialization}

According to our data, only a small portion of ideas (1-2\%) proceed to the industrialization phase, resembling Osterwalder et al. (2020) findings. Thus, the ideas have gone through many evaluation rounds. At this phase, the solution will bear a price tag, and it will be prepared both internally and externally to be marketed, sold, and deployed. However, this process is entirely entrusted to profit-and-loss responsible businesses, and the innovation division is no longer responsible for proceeding with this ready-to-be-sold solution. Interviewed senior project manager described a process rule for the industrialization phase stating that when a solution is entirely entrusted to the business division, it must have cross-functional coordination; additionally, the business owner is solely responsible for any decisions concerning the solution. The boundary rule governing the industrialization phase stated that the solution must be (1) profitable and (2) consistent with its image ("walk the talk"). The preference rule asserted that "resource allocation is based on a solution's gross margin". The schedule rule followed this, namely, "time-to-market dictates resource allocation decisions", as solutions already sold were prioritized over others. For the stop rule, the firm's managers created a simple rule stating that a solution would be abandoned if (1) the customer or (2) the business case fails. Table 3 synthesizes various simple rules at the case company under its new solution development phases. 


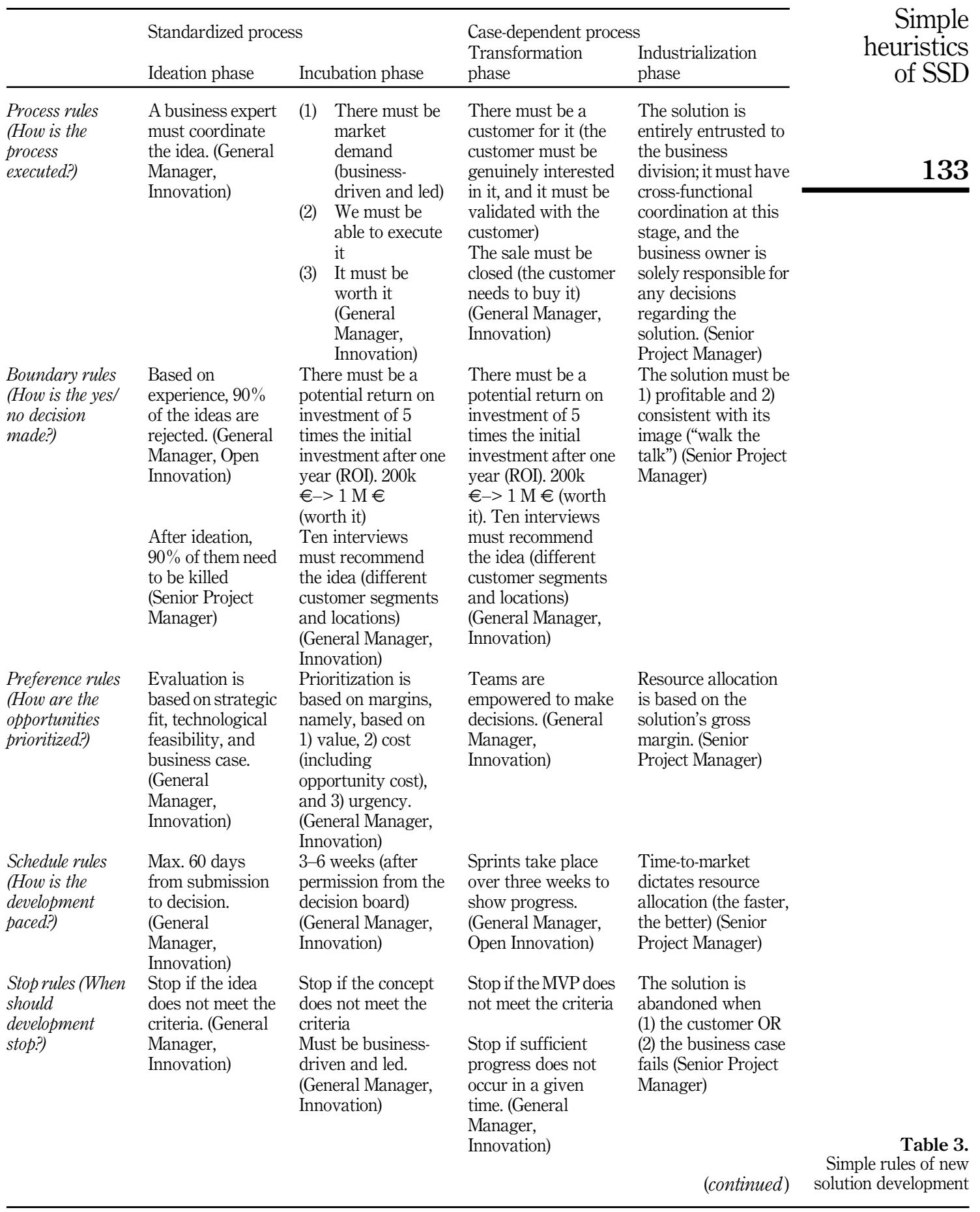




\begin{tabular}{|c|c|c|c|c|c|}
\hline \multirow{2}{*}{$\begin{array}{l}\text { JOSM } \\
33,1\end{array}$} & & \multicolumn{2}{|c|}{ Standardized process } & \multicolumn{2}{|c|}{ Case-dependent process } \\
\hline & & Ideation phase & Incubation phase & $\begin{array}{l}\text { Transformation } \\
\text { phase }\end{array}$ & $\begin{array}{l}\text { Industrialization } \\
\text { phase }\end{array}$ \\
\hline 134 & $\begin{array}{l}\text { The } \\
\text { organizational } \\
\text { target beyond the } \\
\text { phase }\end{array}$ & $\begin{array}{l}\text { Generate more } \\
\text { ideas through an } \\
\text { increased number } \\
\text { of contributors }\end{array}$ & $\begin{array}{l}\text { Obtain faster results } \\
\text { regarding whether } \\
\text { the idea is feasible } \\
\text { and shorten }\end{array}$ & $\begin{array}{l}\text { Increase firm's clock } \\
\text { speed and agility }\end{array}$ & $\begin{array}{l}\text { Increase firm's sales } \\
\text { and profitability }\end{array}$ \\
\hline Table 3. & $\begin{array}{l}\text { Prerequisite/the } \\
\text { outcome of the } \\
\text { process }\end{array}$ & Idea & $\begin{array}{l}\text { Concept and } \\
\text { business case }\end{array}$ & $\begin{array}{l}\text { MVP and Business } \\
\text { plan, MSP }\end{array}$ & Smart Solution \\
\hline
\end{tabular}

4.6 Experiences of a new process model's (early) effects

One driver to establish a more structured development model regarding SSD was to increase development agility. The key target was thus to develop solutions for faster market introduction and improve their success rates through clearer processes and increased collaboration. One innovation manager stated that the project development has become more agile because of new methods: "The whole organization, this is my guess, is going toward agile project management. We have few projects and organizations that have adopted these agile methods". Even though heuristics were not formal, these heuristics evolved based on experiences regarding new solution development projects. Respondents noted that the clock speeds of development projects had increased, and the firm could shorten its innovation cycles. As an illustration of this consequence, people started to talk about days instead of months, as the following quote from one innovation manager exemplifies: "It does not help if you give them three months or three years. If we want something to be ready, then it takes several years ... However, we can get surprisingly much done already within a few days". Furthermore, interviewees emphasized that organizational silos had decreased because of the established development model. The senior project manager emphasized the need to see what is suitable for the entire organization rather than individual (profit-and-loss responsible) units: "We have to get rid of suboptimization. We have to look at the big picture". Overall, even though our research was conducted rapidly after a new innovation process model was established, we were able to obtain some early effects, namely, increased development agility.

\section{Discussion and conclusions}

\subsection{Theoretical contributions}

This study investigates how a manufacturer applies simple rules in its new smart solution development process. There are two major contributions to the new service/solution development literature. First, this study sheds light on the antecedents of strategic agility by demonstrating that managerial heuristics facilitate smart solution development (SSD) agility. Second, this study contributes to the new solution development literature by unfolding dedicated simple rules to manage SSD: process, boundary, preference, schedule, and stop rules.

This study extends the existing literature on (new) smart solution development (Johansson et al., 2019; Hsuan et al., 2021; Schaarschmidt et al., 2018) by demonstrating how simple heuristics facilitate SSD through an in-depth single case study method. Our interpretations support previous findings from Bustinza et al. (2018) that strategic agility is a prerequisite for successfully driving such a strategic change. However, we propose that strategic agility does not drive decision making, but simple heuristics enable more effective 
decision making, thus facilitating the agility of the new solution development process. Thus, adopting simple heuristics shapes strategic decision-making, facilitating the firm's agility regarding new solution development. This agility stems from the interplay of planning and emergence (Mintzberg and Waters, 1985) in organizational decision-making to achieve flexible and controllable organization without red tape and rigidity (Adler and Borys, 1996). When process models dedicated to product business development stress the role of planning, and software development emphasizes fast validation and iterative processes (Immelt, 2017), the simple heuristics approach incorporates both perspectives. Rules can be easily altered when the process experience cumulates or when long-term plans are altered.

As a second theoretical contribution, the present study addresses the call by Paschou et al. (2020) by extending the concept of managerial decision making in the context of new service/solution development (Gremyr et al., 2014; Kindström and Kowalkowski, 2009; Kindström et al., 2013). Our study focused on a specific decisionmaking approach, simple heuristics in the new smart solution development context. Our framework thus provides a useful and practical tool for managers regarding their decision-making by presenting five types of simple heuristics: process, boundary, preference, schedule, and stop heuristics under the smart solution development phases of ideation, incubation, transformation, and industrialization. These dedicated simple rules in each innovation phase reflect that manufacturers increasingly need to rely on a faster and more frugal approach to decision making rather than thicker manuals to guide decision making when the surrounding environment becomes more turbulent and foggier and when the complexity of offerings increases, as is the case with smart solutions and general digitalization megatrends. In particular, the increased role of new smart technologies such as the IoT/AI presents new challenges to decision-making when developing new smart solutions. Heuristic thinking allows a flexible, fast, and ecological way to review this. Furthermore, this approach addresses the observation of Immelt (2017), who calls for manufacturers to become less hierarchical and allow more decentralized decision-making because the software element puts pressure on becoming more agile at the microlevel.

\subsection{Managerial implications}

This study provides a framework of heuristics to improve the management of SSD. The findings provide many heuristics that managers can use and benchmark to find ideas that can work or spur new ones within their own companies. Thus, we encourage managers to consider different types of simple rules, including process, boundary, preference, schedule, and stop heuristics, when developing new smart services/solutions. Establishing formal and well-explicated "simple rules" enables firms to facilitate solution development agility in a flexible yet controllable manner, especially in contexts where the available solution offerings become complex, and the business environment is becoming foggier and more turbulent. Simple rules are essential, especially in contexts where digitalization remarkably shapes firms' business logic, such as in the manufacturing sector, where software is becoming increasingly important strategically and operationally. In general, this study provides a complementary rather than alternative view to review decision making and suggests that experience-based heuristics may overcome traditional rational and slow decision-making approaches in today's rapidly changing business environments shaped by global megatrends. Considering heuristics as a key managerial decisionmaking strategy may help firms outperform their competitors by bringing new solutions faster to the markets and helping firms to (re)allocate their resources more effectively. 
JOSM

33,1

136

\subsection{Limitations and future research avenues}

As with any research, this study has several limitations that need to be acknowledged. The present study focused on interpreting simple heuristics in the context of a single case study. As these rules are not formal and not made explicit and clear for all organization members, our results are interpretative and may contain some response bias. This research is one of the first empirical studies on simple rule heuristics in a new solution development context. Therefore, further studies that use a single case method and multiple cases and quantitative studies are needed (Rabetino et al., 2021b). We also need more information on offering-level issues and how different rules are established to facilitate the development of particular smart solutions. Future studies could thus take the solution as a unit of analysis when studying managerial heuristics. These heuristics can be reviewed retrospectively. Moreover, processual studies can provide interesting opportunities for research on decisionmaking heuristics to study how managers craft these simple rules in practice. Heuristics can also provide further insight into the development of smart solutions by identifying the evolution of heuristics developed in different business circumstances, such as when industries or firms are substantially disrupted. These simple rules address the organizational learning perspective and help answer the following question: "What actual lessons have firms learned along the way when becoming smart solution providers?” Furthermore, service research needs more insight into how heuristic thinking can be applied when innovations are created across firm boundaries. Simple heuristics in open service innovation settings are thus encouraged.

\section{References}

Adler, P.S. and Borys, B. (1996), "Two types of bureaucracy: enabling and coercive", Administrative Science Quarterly, Vol. 41 No. 1, pp. 61-89.

Allmendinger, G. and Lombreglia, R. (2005), "Four strategies for the age of smart services", Harvard Business Review, Vol. 83 No. 10, pp. 131-145.

Antretter, T., Blohm, I., Siren, C., Grichnik, D., Malmstrom, M. and Wincent, J. (2020), "Do algorithms make better - and fairer - investments than angel investors?", Harvard Business Review, available at: https://hbr.org/2020/11/do-algorithms-make-better-and-fairer-investments-thanangel-investors.

Artinger, F., Petersen, M., Gigerenzer, G. and Weibler, J. (2015), "Heuristics as adaptive decision strategies in management", Journal of Organizational Behavior, Vol. 36 No. 1, pp. 33-52.

Bingham, C.B. and Eisenhardt, K.M. (2011), "Rational heuristics: the 'simple rules' that strategists learn from process experience”, Strategic Management Journal, Vol. 32 No. 13, pp. 1437-1464.

Bingham, C.B. and Eisenhardt, K.M. (2014), "Response to Vuori and Vuori's commentary on 'Heuristics in the strategy context”, Strategic Management Journal, Vol. 35 No. 11, pp. 1698-1702.

Bingham, C.B., Howell, T. and Ott, T.E. (2019), "Capability creation: heuristics as microfoundations", Strategic Entrepreneurship Journal, Vol. 13 No. 2, pp. 121-153.

Birkinshaw, J. and Gibson, C. (2004), "Building ambidexterity into an organization", MIT Sloan Management Review, Vol. 45 No. 4, pp. 47-55.

Bustinza, O., Gomes, E., Vendrell-Herrero, F. and Tarba, S. (2018), "An organizational change framework for digital servitization: evidence from the Veneto region”, Strategic Change, Vol. 27 No. 2, pp. 111-119.

Bustinza, O.F., Vendrell-Herrero, F. and Gomes, E. (2020a), "Unpacking the effect of strategic ambidexterity on performance: a cross-country comparison of MMNEs developing productservice innovation”, International Business Review, Vol. 29 No. 6, p. 101569. 
Bustinza, O.F., Vendrell-Herrero, F., Sanchez-Montesinos, F.J. and Campos-Granados, J.A. (2020b), "Should manufacturers support the entire product lifecycle with services?", Sustainability, Vol. 13 No. 5, p. 2493.

Coreynen, W., Matthyssens, P., Vanderstaeten, J. and van Witteloostuijn, A. (2020), "Unravelling the internal and external drivers of digital servitization: a dynamic capabilities and contingency perspective on firm strategy", Industrial Marketing Management, Vol. 89, pp. 265-277.

Corley, K.G. and Gioia, D.A. (2004), "Identity ambiguity and change in the wake of a corporate spinoff", Administrative Science Quarterly, Vol. 49 No. 2, pp. 173-208.

Cui, L., Su, S., Feng, Y. and Hertz, S. (2019), "Causal or effectual? Dynamics of decision making logics in servitization", Industrial Marketing Management, Vol. 82, pp. 6-7.

Dahmani, S., Boucher, X., Gourc, D., Peillon, S. and Marmier, F. (2020), "Integrated approach for risk management in servitization decision-making process", Business Process Management Journal, Vol. 26 No. 7, pp. 1949-1977.

Eisenhardt, K. (1989), "Building theories from case study research", The Academy of Management Review, Vol. 14 No. 3, pp. 532-550.

Eisenhardt, K. and Graebner, M. (2007), "Theory building from cases: opportunities and challenges", Academy of Management Journal, Vol. 50 No. 1, pp. 25-32.

Eisenhardt, K.M. and Sull, D.N. (2001), "Strategy as simple rules”, Harvard Business Review, Vol. 79 No. 1, pp. 106-116.

Eriksson, P. and Kovalainen, A. (2008), Qualitative Methods in Business Research, SAGE Publishing, London.

Gigerenzer, G. (2008), "Why heuristics work”, Perspectives on Psychological Science, Vol. 3 No. 1, pp. 20-29.

Gigerenzer, G. and Gaissmaier, W. (2011), "Heuristic decision making”, Annual Review of Psychology, Vol. 62, pp. 451-482.

Gremyr, I., Witell, L., Löfberg, N., Edvardsson, B. and Fundin, A. (2014), "Understanding new service development and service innovation through innovation modes", Journal of Business and Industrial Marketing, Vol. 29 No. 2, pp. 123-131.

Hastings, R. and Meyer, E. (2020), No Rules Rules: Netflix and the Culture of Reinvention, Penguin Random House UK, New York.

Hsuan, J., Jovanovic, M. and Clemente, D.H. (2021), "Exploring digital servitization trajectories within product-service-software space", International Journal of Operations and Production Management, Vol. 41 No. 5, pp. 598-621, doi: 10.1108/IJOPM-08-2020-0525.

Huberman, M. and Miles, M. (1994), "Data management and analysis methods", in Denzin, N. and Lincoln, Y. (Eds), Handbook of Qualitative Research, Thousand Oaks, London, pp. 428-444.

Huikkola, T. and Kohtamäki, M. (2020), "Agile new solution development in manufacturing companies", Technology Innovation Management Review, Vol. 10 No. 3, pp. 16-24.

Huikkola, T. and Kohtamäki, M. (2021), "Managerial heuristics in servitization journey", in Kohtamäki, M., Baines, T., Rabetino, R., Bigdeli, A.Z., Kowalkowski, C., Oliva, R. and Parida, V. (Eds), The Palgrave Handbook of Servitization, Palgrave Macmillan, Cham, pp. 281-292.

Huikkola, T., Rabetino, R., Kohtamäki, M. and Gebauer, H. (2020), "Firm boundaries in servitization: interplay and repositioning practices", Industrial Marketing Management, Vol. 90, pp. 90-105.

Immelt, J.R. (2017), "How I remade GE: and what I learned along the way", Harvard Business Review, Vol. 95 No. 5, pp. 42-51.

Johansson, A.E., Raddats, C. and Witell, L. (2019), "The role of customer knowledge development for incremental and radical service innovation in servitized manufacturers", Journal of Business Research, Vol. 98, pp. 328-338. 
JOSM 33,1

Jovanovic, M., Raja, J.Z., Visnjic, I. and Wiengarten, F. (2019), "Paths to service capability development for servitization: examining an internal service ecosystem", Journal of Business Research, Vol. 104, pp. 472-485.

Kahneman, D. (2011), Thinking, Fast and Slow, Farrar, Straus and Giroux, New York.

Kahneman, D. and Klein, G. (2009), "Conditions for intuitive expertise: a failure to disagree”, American Psychologist, Vol. 64 No. 6, pp. 515-526.

Kindström, D. and Kowalkowski, C. (2009), "Development of industrial service offerings: a process framework", Journal of Service Management, Vol. 20 No. 2, pp. 156-172.

Kindström, D., Kowalkowski, C. and Sandberg, E. (2013), "Enabling service innovation: a dynamic capabilities approach", Journal of Business Research, Vol. 66 No. 8, pp. 1063-1073.

Kohtamäki, M., Baines, T., Rabetino, R. and Bigdeli, A. (2018), "Practices in servitization", in Kohtamäki, M., Baines, T., Rabetino, R. and Bigdeli, A. (Eds), Practices and Tools for Servitization: Managing Service Transition, Springer International Publishing, London, pp. 1-21.

Kohtamäki, M., Parida, V., Oghazi, P., Gebauer, H. and Baines, T.S. (2019), "Digital servitization business models in ecosystems: a theory of the firm”, Journal of Business Research, Vol. 104, pp. 380-392.

Kohtamäki, M., Einola, S. and Rabetino, R. (2020), "Exploring servitization through the paradox lens: coping practices in servitization", International Journal of Production Economics, Vol. 226.

Kohtamäki, M., Rabetino, R., Einola, S., Parida, V. and Patel, P. (2021), "Unfolding the digital servitization path from products to product-service-software systems: practicing change through intentional narratives", Journal of Business Research, Vol. 137, pp. 379-392.

Korkeamäki, L., Kohtamäki, M. and Parida, V. (2021), "Worth the risk? The profit impact of outcomebased service offerings for manufacturing firms", Journal of Business Research, Vol. 131, pp. 92-102.

Kowalkowski, C. and Ulaga, W. (2017), Service Strategy in Action: A Practical Guide for Growing Your B2B Service and Solution Business, Service Strategy Press, Scottsdale.

Kowalkowski, C., Gebauer, H., Kamp, B. and Parry, G. (2017), "Servitization and deservitization: overview, concepts, and definitions", Industrial Marketing Management, Vol. 60, pp. 4-10.

Kristensson, P. and Magnusson, P. (2019), "Servitization goes to the psychologist: stimulating, realizing and capturing the value from service innovation", in Kristensson, P., Magnusson, P. and Witell, L. (Eds), Service Innovation for Sustainable Business.

Lincoln, Y.S. and Guba, E.G. (1985), Naturalistic inquiry, Sage, Beverly Hills.

Maitland, E. and Sammartino, A. (2015), "Decision making and uncertainty: the role of heuristics and experience in assessing a politically hazardous environment", Strategic Management Journal, Vol. 36 No. 10, pp. 1554-1578.

Markovic, S., Jovanovic, M., Bagherzadeh, M., Sancha, C., Sarafinovska, M. and Qiu, Y. (2020), "Priorities when selecting business partners for service innovation: the contingency role of product innovation”, Industrial Marketing Management, Vol. 88, pp. 378-388.

Mintzberg, H. and Waters, J. (1985), "Of strategies, deliberate and emergent", Strategic Management Journal, Vol. 6 No. 3, pp. 257-272.

Nordin, F. and Kowalkowski, C. (2010), "Solutions offerings: a critical review and reconceptualization", Journal of Service Management, Vol. 21 No. 4, pp. 441-459.

Osterwalder, A., Pigneur, Y., Smith, A. and Etiemble, F. (2020), The Invincible Company: How to Constantly Reinvent Your Organization with Inspiration from the World's Best Business Models, John Wiley \& Sons, Hoboken, New Jersey.

Ott, T.E. and Eisenhardt, K.M. (2020), "Decision weaving: forming novel, complex strategy in entrepreneurial settings", Strategic Management Journal, Vol. 41 No. 12, pp. 2275-2314. 
Paiola, M. and Gebauer, H. (2020), "Internet of things technologies, digital servitization and business model innovation in BtoB manufacturing firms", Industrial Marketing Management, Vol. 89, pp. 245-264.

Palo, T., Ảkesson, M. and Löfberg, N. (2019), "Servitization as business model contestation: a practice approach", Journal of Business Research, Vol. 104, pp. 486-496.

Panesar, S.S. and Markeset, T. (2008), "Development of a framework for industrial service innovation management and coordination”, Journal of Quality in Maintenance Engineering, Vol. 14 No. 2, pp. 177-193.

Paschou, T., Rapaccini, M., Adrodegari, F. and Saccani, N. (2020), "Digital servitization in manufacturing: a systematic literature review and research agenda”, Industrial Marketing Management, Vol. 89, pp. 278-292.

Patton, M.Q. (2002), Qualitative Research and Evaluation Methods, 3rd ed., Sage, Thousand Oaks, CA.

Piekkari, R., Plakoyiannaki and Welch, K. (2010), "Good' case research in industrial marketing: insights from research practice", Industrial Marketing Management, Vol. 39 No. 1, pp. 109-117.

Porter, M.E. and Heppelmann, J.E. (2014), "How smart, connected products are transforming competition”, Harvard Business Review, Vol. 92 No. 11, pp. 64-88.

Porter, M.E. and Heppelmann, J.E. (2015), "How smart, connected products are transforming companies", Harvard Business Review, Vol. 93 No. 10, pp. 96-114.

Pratt, M.G. (2009), "From the editors for the lack of a boilerplate: tips on writing up (and reviewing) qualitative research", Academy of Management Journal, Vol. 52 No. 5, pp. 856-862.

Rabetino, R., Kohtamäki, M. and Gebauer, H. (2017), "Strategy map of servitization", International Journal of Production Economics, Vol. 192, pp. 144-156.

Rabetino, R., Kohtamäki, M., Brax, S.A. and Sihvonen, J. (2021a), "The tribes in the field of servitization: discovering latent streams across 30 years of research", Industrial Marketing Management, Vol. 95, pp. 70-84.

Rabetino, R., Kohtamäki, M., Kowalkowski, C., Baines, T. and Sousa, R. (2021b), "Servitization 2.0: evaluating and advancing servitization-related research through novel conceptual and methodological perspectives", International Journal of Operations and Production Management, Vol. 41 No. 5, pp. 437-464.

Raddats, C., Kowalkowski, C., Benedittini, O., Burton, J. and Gebauer, H. (2019), "Servitization: a contemporary thematic review of four major research streams", Industrial Marketing Management, Vol. 83, pp. 207-223.

Raja, J., Frandsen, T., Kowalkowski, C. and Jarmatz, M. (2020), "Learning to discover value: valuebased pricing and selling capabilities for services and solutions", Journal of Business Research, Vol. 114, pp. 142-159.

Salonen, A. and Jaakkola, E. (2015), "Firm boundary decisions in solution business: examining internal vs. external resource integration”, Industrial Marketing Management, Vol. 51, pp. 171-183.

Schaarschmidt, M., Walsh, G. and Evanschitzky, H. (2018), "Customer interaction and innovation in hybrid offerings: investigating moderation and mediation effects for goods and services innovation”, Journal of Service Research, Vol. 21 No. 1, pp. 119-134.

Siggelkow, N. (2007), "Persuasion with case studies", Academy of Management Journal, Vol. 50 No. 1, pp. 20-24.

Sirén, C., Kohtamäki, M. and Kuckertz, A. (2012), "Exploration and exploitation strategies, profit performance, and the mediating role of strategic learning: escaping the exploitation trap", Strategic Entrepreneurship Journal, Vol. 6 No. 1, pp. 18-41.

Sjödin, D., Parida, V., Jovanovic, M. and Visnjic, I. (2020a), "Value creation and value capture alignment in business model innovation: a process view on outcome-based business models", Journal of Product Innovation Management, Vol. 37 No. 2, pp. 158-183. 
JOSM

33,1

Sjödin, D., Parida, V., Kohtamäki, M. and Wincent, J. (2020b), “An agile co-creation process for digital servitization: a micro-service innovation approach”, Journal of Business Research, Vol. 112, pp. 478-491.

Sklyar, A., Kowalkowski, C., Tronvoll, B. and Sörhammar, D. (2019), "Organizing for digital servitization: a service ecosystem perspective", Journal of Business Research, Vol. 104, pp. $450-460$.

Solem, B.A.A., Kohtamäki, M., Parida, V. and Brekke, T. (2021), "Untangling service design routines for digital servitization: empirical insights of smart PSS in maritime industry", Journal of Manufacturing Technology Management, ahead-of-print.

Storbacka, K. (2011), "A solution business model: capabilities and management practices for integrated solutions”, Industrial Marketing Management, Vol. 40 No. 5, pp. 699-711.

Strauss, A. and Corbin, J. (1998), Basics of Qualitative Research, 2nd ed., Sage, Thousand Oaks, CA.

Sull, D. and Eisenhardt, K.M. (2012), "Simple rules for a complex world", Harvard Business Review, Vol. 90 No. 9, pp. 68-74.

Sull, D. and Eisenhardt, K.M. (2015), Simple Rules: How to Thrive in a Complex World, Hodder Stoughton.

Teece, D. (2007), "Explicating dynamic capabilities: the nature and microfoundations of (sustainable) enterprise performance", Strategic Management Journal, Vol. 28 No. 13, pp. 1319-1350.

Tian, J., Coreynen, W., Matthyssens, P. and Shen, L. (2021), "Platform-based servitization and business model adaptation by established manufacturers", Technovation. doi: 10.1016/j.technovation. 2021.102222 (in press).

Töytäri, P., Turunen, T., Klein, M., Eloranta, V., Biehl, S. and Rajala, R. (2018), “Aligning the mindset and capabilities within a business network for successful adoption of smart services", Journal of Product Innovation Management, Vol. 35 No. 5, pp. 763-779.

Tronvoll, B., Sklyar, A., Sörhammar, D. and Kowalkowski, C. (2020), "Transformational shifts through digital servitization", Industrial Marketing Management, Vol. 89, pp. 293-305.

Tversky, A. and Kahneman, D. (1974), "Judgment under uncertainty: heuristics and biases”, Science, Vol. 185 No. 4157, pp. 1124-1131.

Vendrell-Herrero, F., Bustinza, O.F., Parry, G. and Georganzis, N. (2017), "Servitization, digitization and supply chain interdependency", Industrial Marketing Management, Vol. 60, pp. 69-81.

Vuori, N. and Vuori, T. (2014), "Comment on 'heuristics in the strategy context' by Bingham and Eisenhardt (2011)", Strategic Management Journal, Vol. 35 No. 11, pp. 1689-1697.

Wübben, M. and Wangenheim, F.V. (2008), "Instant customer base analysis: managerial heuristics often 'get it right", Journal of Marketing, Vol. 72 No. 3, pp. 82-93.

\section{Appendix 1}

Semistructured interview template (2016-2018)

\section{Semistructured interview template for senior managers (2016-2018)}

What type of strategic practices are utilized to drive strategic change toward solutions?

Interview questions:

A. Respondent's background

1. How would you describe your current position and your journey to it?

2. If you were selling the firm's strategy, products, services, business model, strengths, and weaknesses to outsiders, such as new shareholders who are not familiar with the industry yet, how would you describe them? 
B. Service business development in manufacturing companies

3. How would you describe the role of services for your company?

4. What kind of tensions or dilemmas you have faced when implementing your service strategy? Please tell some examples of those challenges.

5. If you described the firm's success and competitive advantage, what are the underlying factors behind them? Why has the firm become so successful?

6. How have your competencies changed over the years?

C. Strategy work

7. What issues are emphasized in your strategy? How have these focus areas changed over the years?

8. What kind of practices are utilized in the firm's strategic management?

9. How would you describe your strategy work? What strategy tools do you use?

10. How would you describe strategic thinking in your firm? How has this evolved?

11. What issues are particularly challenging when making strategic decisions? Could you please tell some examples?

D. Smart solutions and dynamic capabilities

12. How do you see the role of new digital technologies such as IoT for your firm in the future?

13. What is the role of the Internet of Things in your strategy?

14. What new competencies are required when digitizing your offerings?

15. Do you need to change your mindset or ways of working when providing digital solutions?

16. How do you build or acquire those competencies?

17. What opportunities do digital technologies provide to you? Do you have any examples of these opportunities?

18. What external resources are critical for you when designing, planning, selling, and implementing digitally enabled solutions? Could you please provide some examples?

19. Have you had to release some assets in order to develop digital solutions?

\section{Appendix 2}

\section{Semi structured interview template (2019-2020)}

\section{Semistructured interview template for senior mana gas (2019-2020)}

What type of practices are utilized to facilitate pro duct-service innovations?

\section{Interview questions:}

A. Background question

1. Please describe firm's (open) pro duct-service innovation development process, how does it differ from traditional innovation process (e.g. in new pro duct development (NPD) or R\&D processes)?

B. Ideation

2. What are the key sources when you gather new ideas? How do customers, suppliers or third-parties contribute to new solution ideation? Any examples? 
JOSM

33,1

142

3. How do you elaborate new ideas? How do you decide that they could be worth taking further?

4. How do you evaluate the feasibility of new ideas? What kind of practices do you have?

5. How do you decide whether to reject or proceed with the idea? What kind of rules of thumb can be utilized in this?

C. Incubation

6. How do you prepare for incubation? How do you utilize other organizations in this phase?

7. How does the sprint takes place? What is the role of other organizations?

8. How do you build a business case? Who can contribute to this?

9. How do you decide whether to reject or proceed in this stage? How do you make sure that there is sufficient demand for this? What kind of practices have you found good to ensure this?

D. Transformation

10. How does the transition to a dedicated transform team take place?

11. Please describe the minimum viable product (MVP) development process? What is the role of external organizations when developing a MVP? How do you know if this will be viable or not?

12. What are good and bad practices for piloting MVP at the customer? Who should be the customer? How do you select it?

13. How do you decide whether to quit or proceed with this MVP? What metrics or rules of thumb do you follow when you decide if MVP will be eventually industrialized?

E. Growth/industrialization

14. How do you decide what further development is needed in the industrialization phase? What is the role of external organizations in this phase?

15. When can you transition from a development team to an industrialization team? When is the solution good enough?

16. What practices have you identified good (or bad) when productizing the solution?

17. How do you learn from successes and failures within the organization and within the network?

\section{Corresponding author}

Tuomas Huikkola can be contacted at: tuomas.huikkola@uwasa.fi

For instructions on how to order reprints of this article, please visit our website:

www.emeraldgrouppublishing.com/licensing/reprints.htm

Or contact us for further details: permissions@emeraldinsight.com 